(6) The most striking feature of the experimental results is, that for all concentrations investigated, the molecular lowering of vapor tension is the same. Thus the lowering of a $0.2 M$ solution is $0.110 \mathrm{~mm}$., while that of the 2.0 M solution is I. I IO2 $\mathrm{mm}$. Similar results have been obtained by Tower and Germann ${ }^{1}$ from a study of the vapor tension of alcoholic solutions of potassium bromide and lithium chloride. Whether this phenomenon can be explained by the combination of the solvent and solute, as suggested by Tower and Germann, cannot be decided until the rigid applicability of Raoult's law has been tested with some nonelectrolyte over the same range of concentration. This the authors purpose doing as soon as possible.

BALTIMORE, MD.

\title{
THE EQUATION OF STATE FOR GASES AND LIQUIDS.
}

By F. H. MacDovgall.

Received October 6, 1915.

Van der Waals' equation, $\left(p+a / v^{2}\right)(v-b)=\mathrm{RT}$, has for thirty years been accepted by chemists and physicists as a most valuable guide in the study of the behavior of gases and liquids. On the other hand, the limitations of the equation of the distinguished Hollander have also come to be generally recognized. From any two of the three quantities, critical temperature, critical pressure and critical volume, the theory of van der Waals enables us to calculate $a$ and $b$. But if from the values of $a$ and $b$ so obtained, we calculate the third critical quantity, our result will be widely at variance with the facts. This is also evident when we remember that the theory of van der Waals requires that the critical density shall be 2.67 times that of an "ideal" gas under the same conditions of temperature and pressure, whereas in all cases hitherto investigated the ratio is much larger, usually about $3 \cdot 7$. Most of the modifications of the equation attempt to meet this condition of affairs, but are unable to raise the ratio above three.

Now there seems to be no doubt that the general ideas underlying the theory of van der Waals are of great value, enabling us to obtain a better insight into the nature of gases and liquids. It would seem to be worth while inquiring whether another method of deriving the equation of state is not theoretically sounder and more justifiable.

Van der Waals' method of applying a correction to the volume of the gas seems to be correct in principle, although the correction represented by the letter $b$ may not be, a "constant." Leaving out of account the surface layer of unknown thickness, the pressure throughout the fluid should undoubtedly be represented by the expression $\mathrm{RT} / v-b$. Owing, however, to unbalanced molecular forces in the surface layer directed to-

1 This Journal, 36, 2449 (1914). 
wards the interior, the external pressure will be less than RT/v $-b$ by the pressure due to the unbalanced molecular forces. Van der Waals assumes this molecular pressure to be represented by $a / v^{2}$ and thus obtains his equation

$$
p=\frac{\mathrm{RT}}{v-b}-\frac{a}{v^{2}}
$$

Now it may well be that in order to obtain the external pressure, we should, instead of subtracting a term from $\mathrm{RT} / v-b$, multiply it by a function, which will of course always be less than unity. This is the result that Dieterici ${ }^{1}$ has obtained, and I shall indicate as briefly as possible his method of reasoning.

In the interior of a fluid the attractive forces between the molecules are balanced; only near the surface are the molecules subject to an unbalanced force directed towards the interior. Molecules with suffciently low velocities moving towards the surface will be unable to reach it, while all molecules moving from the surface towards the interior will be assisted by the force directed inward. The result will be that the density of the surface layer will decrease from the interior towards the surface, where its value will depend on the external pressure. Only molecules having a velocity greater than a certain value will be able to penetrate this inhomogeneous layer and exert a pressure on the walls of the containing vessel. If we can determine what fraction of the total number of molecules has a velocity greater than a fixed value, then the external pressure $(p)$ will be that fraction of the pressure in the interior, RT/v - b. Now if $\alpha$ be the most probable speed, and $s$ be the speed a molecule must possess in order to be able just to penetrate to the surface, then the fraction we are considering is calculated to be $e^{-s^{2} / \alpha^{2}}$, where $e$ is the base of the natural logarithms. If we introduce the speed $c$, the square root of the mean of the squares of the speeds, we have $c^{2}=3 / 2 \alpha^{2}$ and our fraction becomes $e^{-\frac{1 / 2 s^{2}}{1 / c^{2}}}$. If $m$ be the mass of a molecule and $n$ the number of molecules, the expression may be written $e^{-\frac{1 / 2 n m s^{2}}{1 / 3 n m c^{2}}}=$ $e^{-\frac{1 / 2 n m s^{2}}{R T}}$. Now $1 / 2 m s^{2}$ is the work done by a molecule against the molecular forces in reaching the wall; we can therefore write the following equation:

$$
p=\frac{\mathrm{RT}}{v-b} e^{-\mathrm{A} / \mathrm{RT}}
$$

where $\mathrm{A}$ is a measure of the work done by the molecules in penetrating to the surface. If now we make an assumption as to how $A$ depends on the volume, we shall obtain an equation of state. Dieterici assumes that $\mathrm{A}$ is proportional to the density or $\mathrm{A}=a / v$ and thus obtains the Dieterici equation of state

1 Ann. Physik. u. Chem., 11, 700 (1899). 


$$
p=\frac{\mathrm{RT}}{v-b} e^{-a / v \mathrm{RT}}
$$

The object of this paper may be said to be to study this equation in detail and to apply it to a number of well-investigated substances. The results obtained seem worthy of consideration. Dieterici himself showed that his equation reproduces the critical state very well, and in particular gives 3.695 as the value of the ratio $\mathrm{R} \mathrm{T}_{c} / p_{0} v_{c}$, in close agreement with the actual results obtained by Young and others. As far as I can learn from the available literature, Dieterici did not get much farther and has not perstuaded chemists and physicists to adopt his form of the equation of state. One great difficulty in testing the equation lies in the fact that the "constants" $a$ and $b$ are really variables. This has been generally recognized in recent years and the view has been expressed that they are both temperature and volume functions. I hope to show that they are mainly functions of the temperature and that their variation with change in volume is probably small.

Before proceeding to study Dieterici's equation further, it might be well to show its relation to the original one of van der Waals. Dieterici's equation can be written, when the volume $v$ is large as compared with $b$ in the form

$$
p=\frac{\mathrm{RT}}{v-b}\left(\mathrm{I}-\frac{a}{v \mathrm{RT}}\right)=\frac{\mathrm{RT}}{v-b}-\frac{a}{v(v-b)},
$$

which is virtually identical with the van der Waals $p=\mathrm{RT} /(v-b)-$ $a / v^{2}$. It is evident then that all the results obtainable from the van der Waals equation will be deducible from the Dieterici equation when only low pressures are considered. When a gas is under high pressure and, in particular, when the gas is in the critical state, the two equations will differ considerably. And it is to be noted that it is just here that the van der Waals equation loses its validity, while the Dieterici equation reproduces the critical results in most cases with accuracy.

\section{Critical State.}

The values of $p, v$, and $T$ at the critical state in terms of $a, b$ and $R$ are obtained by putting $(d p / d v)_{\mathrm{T}}=0$ and $\left(d^{2} p / d v^{2}\right)_{\mathrm{T}}=0$. If we plot the Dieterici equation having the pressures as ordinates and the volumes as abscissae, we shall get for different values of ' $T$ ' the isothermal curves. The geometrical interpretation of $(d p / d v)_{\mathrm{T}}=0$ is that, when this condition holds, we have a horizontal tangent; that is, the curve has at this point a maximum or minimum value or a point of inflexion. If the second derivative also vanishes for the same values of $v$, the point is a point of inflexion. And that is the critical point. Assuming that $a$ and $b$ are independent of the volume, we obtain the following results: 


$$
\begin{aligned}
&\left(\frac{d p}{d v}\right)_{\mathrm{T}}=-e^{-a / v \mathrm{RT}} \frac{\left(\mathrm{RT} v^{2}-a v+a b\right)}{v^{2}(v-b)^{2}}= \\
&\left(\frac{d^{2} p}{d v^{2}}\right)_{\mathrm{T}}=e^{-a / v \operatorname{RT}}\left[\frac{2 \mathrm{RT}}{(v-b)^{3}}+\frac{p}{\mathrm{RT} v^{4}(v-b)}\left(\mathrm{I}-\frac{a^{2}}{v^{2} \mathrm{R} \mathrm{T}}\right)\right. \\
&\left.\frac{2 a}{v^{3}(v-b)}-\frac{2 a}{v^{2}(v-b)^{2}}\right]
\end{aligned}
$$

Now $(d p / d v)_{T}$ will vanish when $v$ is infinitely great, a value which does not concern us here; when $v$ is equal to zero, which is a physically impossible value since $v$ cannot be less than $b$; and finally when RT $v^{2}-a v+$ $a b=0$. From this equation we obtain

$$
v=\frac{a \pm \sqrt{a^{2}-4} \overline{a b \mathrm{RT}}}{2 \mathrm{RT}} .
$$

This result shows us that there are always two horizontal tangents, real or imaginary or coincident. The two tangents coincide at the critical point and Equation 5 tells us that at this point $a^{2}-4 a b \mathrm{RT}=0$. At the critical point, $a=4 b \mathrm{RT}_{c}$ and therefore the critical temperature $\mathrm{T}_{c}$ is equal to $a / 4 b \mathrm{R}$; at the same time, from Equation 5 we find that the critical volume $v_{c}$ is equal to $a / 2 \mathrm{RT}_{c}$ and therefore equal to $2 b$. Substituting these values in the Dieterici equation of state, we obtain

$$
p_{c}=\frac{\mathrm{RT}_{c}}{e^{2} b}=\frac{2 \mathrm{RT}_{c}}{e^{2} v_{c}}=\frac{a}{4 e^{2} b^{2}}=\frac{a}{29.56 b^{2}} .
$$

Hence $\mathrm{R} \mathrm{T}_{c} / p_{c} v_{c}=e^{\mathrm{e} / 2}=3.695$.

These results could of course have been obtained by combining $(d p / d v)_{\mathrm{T}}=0$ with $\left(d^{2} p / d v^{2}\right)_{\mathrm{T}}=0$, but the method adopted is somewhat simpler. In any case, one can easily satisfy himself that the values obtained for $v_{c}$ and $\mathrm{T}_{c}$ will make both derivatives vanish.

It may be interesting to compare these results with those derived from the original van der Waals equation.

$$
\left.\begin{array}{ll}
\text { Van der Waals. } & \multicolumn{1}{c}{\text { Dieterici. }} \\
v_{c}=3 b & v_{c}=2 b \\
\mathrm{~T}_{c}=8 a / 27 \mathrm{R} b & \mathrm{~T}_{c}=a / 4 \mathrm{R} b \\
p_{c}=a / 27 b^{2} & p_{c}=a / 4 e^{2} b^{2}=a / 29.56 b^{2}
\end{array}\right\}
$$

That the isothermals as given by the Dieterici equation will have the same general appearance as those given by that of van der Waals will be evident if we consider that the condition for a horizontal tangent is given by Equation 5. At the critical temperature the two values of $v$ coincide; above this temperature, $a^{2}-4 a b \mathrm{RT}$ is negative, the two values of $v$ become imaginary; that is, there is no horizontal tangent. Below the critical temperature, however, there are two real and unequal values 
of $v$, corresponding to each of which there is a horizontal tangent on the theoretical isothermal. In other words, the isothermal curve has a maximum and a minimum value. For certain values of $p$, then, horizontal lines may be drawn cutting the isothermal curve in three points, giving three values of $v$ corresponding to the same pressure. It is clear then that the theoretical isothermals as given by the Dieterici equation are quite similar in their general appearance to those of van der Waals.

The following results are set down here, partly for reference, partly so that they may be compared with the well-known deductions from the equation of van der Waals:

$$
\begin{gathered}
p=\frac{\mathrm{RT}}{v-b} e^{-a / v \mathrm{RT}} \\
\left(\frac{d p}{d v}\right)_{\mathrm{T}}=-\frac{e^{-a / v \mathrm{RT}}}{v^{2}(v-b)^{2}}\left(\mathrm{RT} v^{2}-a v+a b\right)= \\
-\frac{p}{v-b}\left[\mathrm{I}-\frac{a(v-b)}{v^{2} \mathrm{RT}}\right] \\
\left(\frac{d p}{d \mathrm{~T}}\right)_{v}=\frac{\mathrm{R}}{v-b}\left(\mathrm{I}+\frac{a}{v \mathrm{RT}}\right) e^{-a / v \mathrm{RT}}=\frac{p}{\mathrm{~T}}\left(\mathrm{I}+\frac{a}{v \mathrm{RT}}\right) \\
\left(\frac{d v}{d \mathrm{~T}}\right)_{p}=\frac{v-b}{\mathrm{~T}}\left(\frac{\mathrm{I}+a / v \mathrm{RT}}{\mathrm{I}-a(v-b) / v^{2} \mathrm{RT}}\right)= \\
\frac{\mathrm{R}}{p} \cdot e^{-a / v \mathrm{RT}} \cdot \frac{(\mathrm{I}+a / v \mathrm{RT})}{\mathrm{I}-a(v-b) / v_{2} \mathrm{RT}}
\end{gathered}
$$

Where $u$ represents the energy of the gas,

$$
\begin{array}{r}
\left(\frac{d u}{d v}\right)_{\mathrm{T}}=\mathrm{T}\left(\frac{d p}{d \mathrm{~T}}\right)_{v}-p=\frac{a p}{v \mathrm{RT}}=\frac{a e^{-a / v \mathrm{RT}}}{v(v-b)}=\frac{a}{v^{2}} \text { (approx.) } \\
C_{p}=C_{v}+\mathrm{R} e^{-a / v \mathrm{RT}} \frac{(\mathrm{I}+a / v \mathrm{RT})^{2}}{\mathrm{I}-a(v-b) / v^{2} \mathrm{R} \mathrm{T}}=C_{v}+\mathrm{R}+\frac{2 a}{v \mathrm{~T}} \text { (approx.) }
\end{array}
$$

Assuming $a$ and $b$ to be functions of $T$,

$$
\left(\frac{d p}{d T}\right)_{v}=\frac{p}{\mathrm{~T}}\left[\mathbf{I}+\frac{a}{v \mathrm{RT}}+\frac{\mathrm{T}}{v-b} \cdot \frac{d b}{d \mathrm{~T}}-\frac{\mathrm{I}}{\mathrm{R} v} \cdot \frac{d a}{d \mathrm{~T}}\right] .
$$

The value of the product $p v$ at constant temperature varies with the pressure $p$. The law governing this relation can be deduced from the Dieterici equation and is as follows:

$$
\left(\frac{d(p v)}{d p}\right)_{\mathrm{T}}=\frac{v^{2}(b \mathrm{RT}-a)+a b v}{v^{2} \mathrm{RT}-a v+a b}
$$

This expression is positive when $b \mathrm{R}^{\prime} \mathrm{T}>a$, or $b>a / \mathbf{R} T$, as must be the case with hydrogen at ordinary temperatures and even at as low a temperature as $-147^{\circ}$. If, however, $a / \mathrm{RT}$ is greater than $b$, the expression is at first negative for small values of $p$, becomes equal to zero and finally 
positive when $p$ is sufficiently increased or $v$ sufficiently diminished. When the expression becomes zero, we have a minimum value of $p$. The condition for this minimum is obtained by putting $v^{2}(b \mathrm{RT}-a)+$ $a b v$ equal to zero. Neglecting the impossible value, $v=0$, we arrive at the following relations which hold when $p v$ has its minimum value:

$$
\begin{gathered}
v=a b /(a-b \mathrm{RT}) \\
p v_{(\min .)}=\frac{a}{b} e^{1-a / b \mathrm{RT}} \\
p=\frac{a-b \mathrm{RT}}{b^{2}} e^{1-a / b \mathrm{RT}}
\end{gathered}
$$

Equations I2, I3 and I4 can be used in calculating the values of $a$ and $b$, above the critical temperature.

When $a$ is greater than $b \mathrm{RT}$, as we have seen, $p v$ at first diminishes as $p$ increases; when $a$ is less than $b \mathrm{RT}, p v$ increases with $p$. When $a=b \mathrm{R} T, i$. $e_{:}$, when $\mathrm{T}=a / \mathrm{R} b$, the minimum $p v$ would occur when $v=$ infinity and $p=0$; in other words, at this temperature the minimum just fails to appear and the po curve wonld be a horizontal straight line for a short distance. Under these conditi, s, th is would follow Boyle's law with great accuracy. If $a$ and $b$ were inder-u snt of the temperature, we should be able to calculate the temperature at'which a gas would obey Boyle's law accurately as equal to four times the critical temperature. Since $a$ and $b$ are functions of the temperatire, the temperature calculated in this manner will be usually quite in error. In cases where this temperature is known accurately for any gas, we have a means of finding the value of the ratio $a / b$ at this temperature, for the relation $a=b \mathrm{RT}$ may be written

$$
a / b=\mathrm{RT} \text {. }
$$

As an example, Young, on page 34 of his "Stoichiometry" states that at about $52^{\circ}, d(p v) / d p$ for nitrogen is equal to zero. Accordingly at this temperature, the ratio $a / b=325 / 273=1.19$, when the unit mass of nitrogen is that which occupies unit volume at zero, and a pressure of one atmosphere.

Equation II can be simplified for the case that the pressures obtaining are small and the volumes large. We obtain, then,

or

$$
\frac{d(p v)}{d p}=\frac{v^{2}(b \mathrm{R} T-a)}{v^{2} \mathrm{RT}}=b-\frac{a}{\mathrm{RT}}
$$

$$
\frac{p_{2} v_{2}-p_{1} v_{1}}{p_{2}-p_{1}}=b-\frac{a}{\mathrm{RT}}
$$

This equation may also be obtained directly from the Dieterici equation, which for low pressures may be written, $p v=\mathrm{R} T+p b-a / v$. 
Hence $p_{2} v_{2}-p_{1} v_{1}=\left(p_{2}-p_{1}\right) b-\left(\mathrm{I} / v_{2}-\mathrm{I} / v_{1}\right) a=\left(p_{2}-p_{1}\right)(b-a / \mathrm{RT})$ and finally Equation 16.

\section{PV Curve at the Critical Temperature.}

Some interesting results are obtained by applying Equations I2, I3 and $I_{4}$ when the gas is at the critical temperature. In this case, when $p v$ has its minimum value, the following relations hold:

$$
\left.\begin{array}{c}
v=4 / 3 b=2 / 3 v_{c} \\
p=3 a / 4 e^{3} b^{2}=3 / e p_{c}=1.104 p_{c} \\
p v_{\min .}=a / e^{3} b=2 / e p_{c} v_{c}=4 / e^{3} \mathrm{RT}_{c}=0.736 p_{c} v_{c}=0.199 \mathrm{I} \mathrm{RT}_{c}
\end{array}\right\}
$$

The above results may be expressed in words as follows: At the critical temperature, the minimum value of $p v$ is about $3 / 4$ of its value in the critical state, and about $1 / 5$ of its "theoretical" value; the corresponding volume is $2 / 3$ of the critical volume, and the corresponding pressure is about $10 \%$ greater than the critical pressure. It might also be added that Dieterici's equation for the critical isothermal becomes

$$
p=a / 4 b(v-b) e^{-4 b / v}
$$

which for low pressures is equivalent to

$$
p(v+3 b)=\mathrm{RT}_{c} \text {. }
$$

\section{Negative Pressures Impossible.}

Returning to a consideration of Equation 5, we said that the two values of $v$ given by this equation correspond to the maximum and minimum pressures on any theoretical isothermal. As is well known, on using van der Waals' equation, the theoretical minimum pressure is frequently negative, since the term $a / v^{2}$ may easily become greater than the term $\mathrm{RT} /(v-b)$. Using the Dieterici equation, the external pressure (for that is what $p$ refers to) becomes zero only at the absolute zero of temperature and under no circumstances becomes negative. Young, ${ }^{1}$ describes an experiment by Worthington, ${ }^{2}$ in which a sealed tube completely full of a pure liquid is cooled slowly. He finds that in some experiments the thick-walled tube actually collapsed owing to what he calls the enormous tension. Now on both van der Waals' theory and on that of Dieterici, it is assumed that there is no attractive force between the molecules of the fluid and the wall. The only force assumed at the boundary is that due to the bombardment of the wall by the molecules which reach the surface. The hydrostatic pressure may be here neglected. In the absence of any adhesive force between the fluid and the wall, a negative external pressure is inconceivable. For, assume that under given conditions, the pressure directed towards the interior and due to molecular attraction is equal to po. The pressure on any imaginary unit area in the interior will still be given

1 "Stoichiometry," 1908, p. 205.

2 Phil. Trans., $(A)$ 183, 355 (1892). 
by $\mathrm{RT} /(v-b)$. Van der Waals' equation requires us to imagine that under certain circumstances $p_{0}$ is greater than $\mathrm{RT} /(v-b)$. What would be the result? The result would be that more molecules would move from the surface layers to the interior than in the opposite direction. This would mean that the volume of the fluid would decrease until $\mathrm{RT} /(v-b)$ became greater than $p$, since $\mathrm{RT} /(v-b)$ must be greater than $p_{0}$ in order that the number of molecules moving in the two directions shall be equal. For molecules moving towards the surface layer have to overcome a force, while those moving into the interior from the surface are moving in the same direction as the force. The phenomena described by Worthington then cannot be explained on the fundamental assumptions either of van der Waals or of Dieterici which do not consider any attractive forces between the fluid and the wall.

\section{Maximum and Minimum Pressures.}

We obtain the theoretical maximum and minimum pressures on any isothermal curve by substituting in the Dieterici equation the two values of $v$ from Equation 5. Thus:

$$
\begin{aligned}
& p_{\text {max. }}=\frac{2 \mathrm{R}^{2} \mathrm{~T}^{2}}{a-b \mathrm{RT}+\sqrt{a^{2}-4 a b \mathrm{RT}}} e^{-\frac{2 a}{a+\sqrt{a^{2}-4 a b \overline{\mathrm{RT}}}}} \\
& p_{\text {min. }}=\frac{2 \mathrm{R}^{2} \mathrm{~T}^{2}}{a-b \mathrm{RT}-\sqrt{a^{2}-4 a b \mathrm{RT}}} e^{-\frac{2 a}{a-\sqrt{a^{2}-4 a b \mathrm{R} T}}}
\end{aligned}
$$

Also

and therefore

$$
p_{\max .} \times p_{\min .}=\frac{\mathrm{R}^{2} \mathrm{~T}^{2}}{b^{2}} e^{-a / b \mathrm{RT}^{T}}
$$

$$
\sqrt{p_{\max }} \times \overline{p_{\min }}=\frac{\mathrm{RT}}{b} e^{-a / 2 b \mathrm{RT}}
$$

According to Equation $19 c$, the geometric mean of the maximum and minimum pressure on any isothermal is the pressure corresponding to the volume $2 b$. At the critical temperature, this volume would be the critical volume and the pressure, the critical pressure. At a lower temperature, the value of $2 b$ will be different from the critical volume, since we shall see that $b$ is a function of the temperature. We shall now proceed to discuss a method of determining the value of $b$ at different temperatures.

\section{Determination of $b$ at Different Temperatures.}

If a substance is at a temperature lower than its critical temperature, experience teaches us that a certain portion of the theoretical isothermal curve is not realizable. Instead of the pressure increasing to a maximum, falling to a minimum and then increasing indefinitely as the volume is decreased, the pressure increases to a certain value and then remains constant until 
the gas is completely condensed into liquid. If this line of constant pressure be drawn in our pv diagram, it will cut the theoretical isothermal in three points; and we know from thermodynamics that the two areas bounded by the isothermal and the horizontal line, one above this line and the other under it, are equal. Two of the points correspond to the volumes of the liquid and the saturated vapor, the third point on our continuous isothermal corresponds in practice to a state in which both liquid and vapor are present. Let $v_{1}, v_{2}$ and $v_{3}$ represent the volumes of the liquid, vapor and the third intermediate volume, all corresponding to the pressure of the saturated vapor. We have then the equations

$$
p_{s}=\frac{\mathrm{RT}}{v_{1}-b} e^{-\frac{a}{v_{2} \mathrm{RT}}}=\frac{\mathrm{RT}}{v_{2}-b} e^{-\frac{a}{v_{2} \mathrm{RT}}}=\frac{\mathrm{RT}}{v_{3}-b} e^{-\frac{a}{v_{3} \mathrm{RT}}} .
$$

Evidently the product of the second and third expressions is equal to the square of the fourth. We thus obtain

$$
\frac{\mathrm{I}}{\left(v_{1}-b\right)\left(v_{2}-b\right)} e^{-\frac{a}{\mathrm{RT}}\left(\frac{1}{v_{1}}+\frac{1}{n_{2}}\right)}=\frac{\mathrm{I}}{\left(v_{3}-b\right)^{2}} e^{-\frac{a}{\mathrm{RT}}} \cdot \frac{2}{v_{2}} .
$$

Now if we make the assumption that $I / v_{1}+I / v_{2}=2 / v_{3}$, then, of course, $\left(v_{1}-b\right)\left(v_{2}-b\right)=\left(v_{2}-b^{2}\right)$. From these two relations the following results are easily deduced:

$$
\begin{gathered}
v_{3}=2 b \\
1 / b=1 / v_{1}+1 / v_{2} \\
v_{1}=\frac{b v_{2}}{v_{2}-b} ; v_{2}=\frac{b v_{1}}{v_{1}-b} \\
\frac{v_{2}}{v_{1}}=\frac{v_{2}-b}{b}=\frac{b}{v_{1}-b} \\
\left(\frac{v_{2}}{v_{1}}\right)^{2}=\frac{v_{2}-b}{v_{1}-b}
\end{gathered}
$$

And finally, for the pressure at which liquid and vapor are in equilibrium, since $v_{3}=2 b$, we obtain

$$
p_{s}=\frac{\mathrm{RT}}{b} e^{-\frac{a}{2 b \mathrm{RT}}} .
$$

Comparing Equations 22 with $19 c$, we see that the pressure at which liquid and vapor are in equilibrium at any temperature is equal to the geometric mean of the maximum and minimum pressures on the theoretical isothermal for that temperature. Making use of Equation $2 \mathrm{I} b$, and letting $d_{1}$ and $d_{2}$ stand for the densities of liquid and saturated vapor, Equation 22 may be written as follows:

$$
\begin{gathered}
p_{s}=\left(\frac{\mathrm{I}}{v_{1}}+\frac{\mathrm{I}}{v_{2}}\right) \mathrm{RT} \cdot e^{-\frac{a}{2 \mathrm{RT}}\left(\frac{1}{a_{1}}+\frac{1}{v_{2}}\right)} \\
p_{s}=\left(d_{1}+d_{2}\right) \mathrm{RT} \cdot e^{-\frac{a\left(d_{s}+d_{2}\right)}{2 \mathrm{RT}}}
\end{gathered}
$$


The above results have been obtained on the assumption that $2 / v_{3}=$ $\mathbf{r} / v_{1}+\mathrm{I} / v_{2}$. Any of the equations numbered $2 \mathrm{I}$ would of course be an equivalent assumption, such as, for example, that $v_{3}=2 b$. Our assumption may also be written in the form $d_{3}=\left(d_{1}+d_{2}\right) / 2$, i. e., the third point on the theoretical isothermal cut by the line of constant pressure would represent a density which is the arithmetic mean of the densities of liquid and the saturated vapor. Now what grounds are there for this assumption? In the first place, at the critical temperature, $v_{1}, v_{2}$ and $v_{3}$ are all equal to $2 b=v_{c}$. As the temperature is decreased, $v_{1}$ decreases fairly rapidly and $v_{2}$ increases quite rapidly, while the intermediate volume, $v_{3}$, might be expected to change very slowly. And in fact, if a $p v$ diagram containing a number of isothermals below the critical temperature be examined, it will be seen that the point where the line of constant pressure cuts the descending portion of the isothermal represents a volume which does not differ much from the critical volume; that is, $v_{3}$ does not differ very much, as the temperature decreases, from $v_{c}=2 b_{c}$, where $b_{c}$ is the value of $b$ at the critical temperature. It seemed very plausible to assume that $u_{s}$ is equal to $2 b$ at every temperature, although not necessarily equal to $2 b_{c}$.

Another circumstance which led me to the assumption that $2 / v_{3}=$ $\mathrm{I} / v_{1}+\mathrm{I} / v_{2}$ was a consideration of the law of Cailletet and Mathias, ${ }^{1}$ according to which the mean of the densities of liquid and saturated vapor is a linear function of the temperature, a statement therefore which would hold for $d_{3}$ or $\left(d_{1}+d_{2}\right) / 2$. Expressed in our symbols, then, $d_{3}=$ $d_{0}+\alpha \mathrm{T}$, where $\alpha$ is always very small. The fact that $\left(d_{1}+d_{2}\right) / 2$ is so nearly constant, varying only slightly and uniformly with the temperature seemed to me to be of great significance. If the mean of the densities of liquid and saturated vapor is given by such a simple relation, it seemed plausible to assume that this mean is identical with that given by the third point on the theoretical isothermal. Additional support to the assumption is given by the fact that we found the geometric mean of the maximum and minimum pressures on any theoretical isothermal to be equal to $\frac{\mathrm{RT}}{b} \cdot e^{-\frac{a}{2 b \mathrm{RT}}}$ (cf. Equation 19c). Now this is exactly the same pressure which we calculate to be the pressure of saturated vapor, when we assume that $v_{8}=2 b$. It seems fair to assume that this result is not simply a chance mathematical agreement, but that it corresponds to some physical reality. However insufficient the grounds for this assumption may be, $I$ have adopted it in this paper.

Young ${ }^{2}$ has shown that in the equation representing the law of Cailletet and Mathias, which may be written in the form $s_{\mathrm{T}}=s_{0}+\alpha \mathrm{T}$, the value

1 Compt. rend., 102, 1202 (1886).

2 "Stoichiometry," p. 228. 
of $\left(-\alpha \mathrm{T} c / s_{c}\right)$ is approximately unity for a large number of substances. In this equation, $s_{\mathrm{T}}=\left(d_{1}+d_{2}\right) / 2$ and $s_{c}$ is the critical density, and $s_{0}$ would be equal to half the density of the liquid at absolute zero, since at this temperature the density of the vapor would be zero. If the law of Cailletet and Mathias is assumed to hold accurately down to absolute zero and if the value of $\left(-\alpha \mathrm{T}_{c} / s_{c}\right)$ is exactly unity, one can easily deduce that at the absolute zero, the density of a substance would be four times the critical density. Again, since $s_{\mathrm{T}}=\left(d_{1}+d_{2}\right) / 2=1 / 2 b$, we can obtain the following result:

$$
b_{\mathrm{T}}=\frac{b_{c}}{\left(2-\mathrm{T} / \mathrm{T}_{c}\right)}
$$

This result holds only for those substances for which the law of Cailletet and Mathias is valid and for which $\left(-\alpha \mathrm{T}_{c} / s_{c}\right)$ is approximately unity.

It might be added that Thorpe and Rücker's formula ${ }^{1}$ for estimating the critical temperature is easily deducible, if we assume the law of Cailletet and Mathias and that $\left(-\alpha \mathrm{T}_{c} / s_{c}\right)$ is approximately unity. For if $d_{1}$ and $d_{2}$ now represent the densities of a liquid at the two temperatures $T_{1}$ and $T_{2}$, sufficiently below the critical temperature, the densities of saturated vapor may be neglected and we obtain $d_{1}=2 s_{\mathrm{T}_{1}}$. Accordingly $d_{1}=2 s_{c}\left(2-\mathrm{T}_{1} / \mathrm{T}_{c}\right)$ and $d_{2}=2 s_{c}\left(2-\mathrm{T}_{2} / \mathrm{T}_{c}\right)$, from which we easily obtain

$$
\frac{\mathrm{T}_{2} d_{1}-\mathrm{T}_{1} d_{2}}{2\left(d_{1}-d_{2}\right)}=\mathrm{T}_{c}
$$

Now Thorpe and Rücker's formula is

$$
\mathrm{T}_{c}=\frac{\mathrm{T}_{2} d_{1}-\mathrm{T}_{1} d_{2}}{\mathrm{~A}\left(d_{1}-\frac{\left.d_{2}\right)}{d_{2}}\right.}
$$

where A varies from 1.926 to 2.030 for 24 substances with a mean value of 1.974 .

From the relation

\section{Determination of $a$.}

$$
p_{s}=\frac{\mathrm{RT}}{v_{1}-b} e^{-\frac{a}{v_{1} \mathrm{RT}}}=\frac{\mathrm{RT}}{v_{2}-b} e^{-\frac{a}{v_{3} \mathrm{RT}}}
$$

we obtain

$$
a_{1}=\frac{v_{1} v_{2}}{v_{2}-v_{1}} \text { RT } \log _{e} \frac{v_{2}-b}{v_{1}-b},
$$

or since, according to Equation $2 \mathrm{r} e,\left(v_{2}-b\right) /\left(v_{1}-b\right)=\left(v_{2} / v_{1}\right)^{2}$,

$$
a_{1}=\frac{2 v_{1} v_{2}}{v_{2}-v_{1}} \mathrm{RT} \log _{e} \frac{v_{2}}{v_{1}} .
$$

Expressed in terms of the densities $d_{1}$ and $d_{2}$, Equation 26 becomes

1 Quoted in Young's "Stoichiometry," p. I 83. 


$$
a_{1}=\frac{2 \mathrm{RT}}{d_{1}-d_{2}} \log _{e} \frac{d_{1}}{d_{2}} \text {. }
$$

I have called the " $a$ " of Equations 26 and $26 a, a_{1}$, since $a$ can be calculated in several other ways. From the set of Equations 20, we obtain the following (since $v_{3}=2 b$ ):

$$
\begin{aligned}
& a_{2}=2 b \mathrm{RT} \log _{e} \mathrm{RT} / p b \\
& a_{3}=v_{1} \mathrm{RT} \log _{e} \mathrm{RT} / p\left(v_{1}-b\right) \\
& a_{4}=v_{2} \mathrm{RT} \log _{e} \mathrm{RT} / p\left(v_{2}-b\right)
\end{aligned}
$$

An investigation of Equations 26-29 will show that Equation 29 is likely to be the least accurate. In the first place $p\left(v_{2}-b\right)$ is very nearly equal to RT, so that the logarithm of their quotient, which is the same as the difference of their logarithms, will be greatly affected by small errors in the assumed values of $p$ and $v_{2}$. As regards an error in the value of $p$, its effect on $a_{4}$ will be $v_{2} / v_{1}$ times as great as on $a_{3}$. Then there is no doubt that usually $v_{1}$ is determined more accurately than $v_{2}$.

Another method which I have used in calculating $a$ and $b$ for hydrogen is based on Equation 7 or $7 a$. By Equation 7

$$
\mathrm{I}+\frac{a}{v \mathrm{R} T}=\frac{d p / d \mathrm{~T}}{p / \mathrm{T}}=\frac{\mathrm{T} d p}{p d \mathrm{~T}}=\frac{d \log p}{d \log \mathrm{T}} .
$$

If the variation of $a$ and $b$ with the temperature be taken into account, we have

$$
\mathrm{I}+\frac{a}{v \mathrm{RT}}+\frac{\mathrm{T}}{v-b} \frac{d h}{d \mathrm{~T}}-\frac{\mathrm{I}}{v \mathrm{R}} \frac{d a}{d \mathrm{~T}}=\frac{d \log p}{d \log \mathrm{T}} .
$$

If in any particular case, $a$ and $b$ are independent of the temperature, or if the expression $\left(\frac{\mathrm{T}}{v-b} \frac{d b}{d t}-\frac{\mathrm{I}}{v \mathrm{R}} \frac{d a}{d \mathrm{~T}}\right)$ is equal to zero, then, the simpler Equation 30 may be employed in determining $a$, and hence $b$.

\section{Latent Heat of Vaporization.}

In order to determine the latent heat of vaporization, we must calculate the work that is done when the liquid expands isothermally from the volume $v_{1}$ to the volume $v_{2}$. This takes place in practice under the constant external pressure of saturated vapor, $p_{s}$. The same work will be done if the expansion is supposed to follow the course of the theoretical isothermal curve. The total work will be expressed by the definite integral

$$
\mathrm{L}=\int_{v_{2}}^{v_{2}} \frac{\mathrm{RT}}{v-b} \cdot d v=\mathrm{RT} \log _{e} \frac{v_{2}-b}{v_{1}-b}=2 \mathrm{RT} \log _{e} \frac{v_{2}}{v_{1}},
$$

if we make use of Equation $2 \mathrm{re}$. $\mathrm{RT} /(v-b)$ represents the pressure throughout the fluid except in the surface layer which is negligible. Accordingly $\frac{\mathrm{R} T}{v-b} d v$ represents the total work done when the volume 
increases by the increment $d v$. Equation 3 I includes the external work, the amount of which is $p\left(v_{2}-v_{1}\right)$. Hence the internal heat of vaporization would be

$$
I=2 \mathrm{RT} \log _{e} \frac{v_{2}}{v_{1}}-p\left(v_{2}-v_{1}\right) .
$$

Comparing Equation 31 with Equation 26, we see that we may write

$$
\mathrm{L}=2 \mathrm{R} T \log _{e} \frac{v_{2}}{v_{1}}=\frac{a}{v_{1}}-\frac{a}{v_{2}}
$$

The expression $a / v_{1}-a / v_{2}$ is accordingly a measure of the total heat of vaporization, whereas according to the theory of van der Waals it measures the internal heat of vaporization only. Equation 32 agrees with the assumption made by Dieterici in deriving his original equation that the work done by the molecules in penetrating the surface layer is equal to $a / v$. According to Kendall, ${ }^{1}$ Dieterici has proposed a formula, $\mathrm{I}=c \mathrm{RT}$ $\log v_{2} / v_{1}$ for the internal heat of vaporization. I have not yet been able to obtain a copy of the article in which this formula is deduced; it is, however, to be noted that it is Dieterici's formula for the internal heat of vaporization which is similar to mine for the total effect.

\section{Joule-Thomson Effect.}

Our methods of arriving at values of $a$ and $b$ may be summarized as follows: At the critical temperature, $a$ and $b$ can be calculated from the critical data according to equations numbered 6 . Above the critical temperature, so long as $p v$ still has a minimum value, use may be made of Equations 12, 13 and 14. Below the critical temperature, Equations $2 \mathrm{I} b$ and 26 to 29 are to be employed. And of course Equations 30 and $30 a$ are valid at all temperatures and can be used where the data are sufficiently accurate. Another method of finding a relationship between $a$ and $b$ is based on the Joule-Thomson effect. If $\Delta T$ be the change in temperature, $\Delta p$ the change in pressure, in the Joule-Thomson experiments, we have the following relation:2

$$
\Delta \mathrm{T}=\frac{\mathrm{T}(d v / d \mathrm{~T})_{p}-v}{c_{p}} \cdot \Delta p
$$

If we substitute for $(d v / d \mathrm{~T})_{p}$, the value given by Equation 8 , we obtain the following approximate result:

$$
\Delta \mathrm{T}=\frac{2 a / \mathrm{RT}-b}{c_{p}} \cdot \Delta p
$$

Equation 34 will hold most accurately when only low pressures are employed. It is identical with the formula derived by van der Waals from his original equation, as we should expect. If the ration $\Delta \mathrm{T} / \Delta p$ is de-

1 This Journat, 36, 1620 (1914).

2 Planck, "Thermodynamik," 1905, p. 123. 
termined accurately at any temperature, we have a means of calculating $2 a / \mathrm{RT}-b$; while by using Equation I 6 we can obtain the value of $b-a /$ RT. Hence we can find $a$ and $b$. Further discussion of these points will appear when we apply our equations to the experimental results.

\section{Applications.}

In this paper I have taken $-273.09^{\circ} \mathrm{C}$. as the absolute zero of temperature and $224 \mathrm{r} 2 \mathrm{cc}$. as the volume of a gram-molecule of an ideal gas under the pressure of one atmosphere. ${ }^{1}$ The value assumed for the constant $\mathrm{R}$ for a $\mathrm{mol}$ is $6237^{2}$ when a mm. of mercury is the unit of pressure, 82.07 when the unit of pressure is one atmosphere. The unit of volume is always one cubic centimeter. When the equations apply to a mass of gas whose volume is considered to be unity when the pressure is one atmosphere and the temperature is $0^{\circ} \mathrm{C}$., the value of $\mathrm{R}$ is approximately I $/ 273$.

Isopentane.-Tables I and II contain the results of applying our equations to isopentane. The data for the specific volumes of liquid and saturated vapor are by Young as given in Landolt-Börnstein's Tabellen. ${ }^{2}$ The observed pressures are also by Young and are taken from an article by Dieterici. ${ }^{3}$ The results refer to I $\mathrm{g}$. of the substance; pressures are given in millimeters of mercury. Accordingly the value of the constant $R$ is $62372 / 72.09$. The orthobaric volumes of liquid and vapor are represented by $v_{1}$ and $v_{2}$, respectively; $b$ is calculated using Equation $2 \mathrm{I} b$, and $a_{1}, a_{2}, a_{3}$, and $a_{4}$ by means of Equations 26 to 29 .

\begin{tabular}{|c|c|c|c|c|c|c|c|}
\hline$t^{\circ} \mathrm{C}$ & $\begin{array}{c}v_{1 .} \\
\text { cc. } \\
\text { I. } 5642\end{array}$ & $\begin{array}{r}\text { e. } \\
c \varepsilon \\
909\end{array}$ & $\begin{array}{l}b . \\
\text { cc. } \\
\text { I. } 56 \text { I } 5\end{array}$ & $\begin{array}{c}a_{1} \times 10^{-8} . \\
4.713\end{array}$ & $\begin{array}{c}0 \times 100 \\
4.704\end{array}$ & $\begin{array}{r}0.8 \times 10^{-6} \\
4.708\end{array}$ & $\begin{array}{r}a \times 10^{-6} \\
2.223\end{array}$ \\
\hline 20 & 1.6140 & 426.6 & I. 6079 & $4 \cdot 583$ & $4 \cdot 5^{82}$ & $4 \cdot 5^{82}$ & 4.450 \\
\hline 40 & 1. 6700 & 224.4 & I. 6577 & $4.46 \mathrm{I}$ & 4.466 & 4.467 & 4.434 \\
\hline 60 & I. 7334 & 127.6 & I. 7102 & $4 \cdot 354$ & 4.353 & 4.354 & 4.310 \\
\hline 80 & I. $805 \mathrm{I}$ & $77 \cdot 700$ & I. 7641 & 4.248 & 4.236 & 4.242 & 3.987 \\
\hline 100 & 1.8947 & 49.505 & 1.8248 & 4.150 & 4.120 & 4.135 & 3.747 \\
\hline rro & I. 9455 & 39.793 & I, 8548 & 4.093 & 4.059 & 4.075 & 3.727 \\
\hline 120 & 2.0036 & $32 \cdot 196$ & I. 8862 & 4.036 & 3.991 & 4.012 & 3.650 \\
\hline I 30 & $2.072 \mathrm{I}$ & 26.103 & I.9197 & 3.977 & 3.922 & $3.94^{8}$ & 3.604 \\
\hline 140 & 2. 1542 & 21.151 & $\mathrm{I} .955 \mathrm{I}$ & 3.916 & 3.860 & $3.88 \mathrm{I}$ & $3 \cdot 564$ \\
\hline I5O & 2.2497 & 17.141 & I. 9887 & 3.850 & 3.771 & 3.806 & 3.512 \\
\hline 160 & 2.3776 & 13.719 & 2.0264 & 3.778 & 3.690 & 3.726 & 3.480 \\
\hline I 70 & 2.5549 & 10.710 & 2.0628 & 3.687 & 3.599 & 3.633 & 3.459 \\
\hline 180 & 2.8588 & $7 \cdot 9491$ & 2.1026 & 3.579 & 3.503 & 3.528 & 3.436 \\
\hline 183 & 3.0202 & 7.0522 & 2. II 46 & 3.535 & 3.473 & 3.491 & 3.432 \\
\hline I 86 & 3.3025 & 5.9666 & 2.1258 & $3 \cdot 47^{6}$ & $3 \cdot 44 I$ & 3.449 & $3 \cdot 428$ \\
\hline $\mathrm{r} 87.8$ & 4.2680 & 4.2680 & 2.1340 & 3.404 & 3.423 & 3.423 & 3.423 \\
\hline
\end{tabular}




\begin{tabular}{|c|c|c|c|c|c|c|}
\hline $\begin{array}{c}t^{\circ} \mathrm{C} \\
0\end{array}$ & $\begin{array}{l}p \text { (obs.). } \\
257.7\end{array}$ & $\begin{array}{c}p=\frac{\bar{b}}{2}-\overline{2 b \mathrm{RT}} \\
254.7\end{array}$ & $\begin{array}{c}\% \text { error. } \\
\text { I. } 2\end{array}$ & $\begin{array}{c}a_{1} \times 6 \times 10^{-6} \\
7.35\end{array}$ & $\begin{array}{c}\text { L (calc.). } \\
95.8\end{array}$ & $\begin{array}{c}\text { L (Young) } \\
86.8\end{array}$ \\
\hline 20 & 572.6 & 571.9 & 0.1 & $7 \cdot 36$ & 90.0 & 82.9 \\
\hline 40 & 1131 & 1134 & 0.3 & 7.40 & 84.5 & 78.8 \\
\hline 60 & 2036 & 2034 & 0.1 & 7.45 & 78.9 & 74.4 \\
\hline 80 & $340 I$ & 3364 & 1.1 & $7 \cdot 30$ & 73.2 & 69.8 \\
\hline 100 & 5355 & 5222 & 2.5 & $7 \cdot 58$ & $67 . I$ & 64.6 \\
\hline IIO & 6586 & 6406 & 2.7 & $7 \cdot 59$ & 63.7 & 61.7 \\
\hline 120 & 8040 & 7762 & 3.4 & 7.62 & 60.1 & 58.5 \\
\hline 130 & 9707 & 9317 & 4.0 & 7.63 & 56.2 & 54.8 \\
\hline I 40 & I 1620 & I I09 I & 4.5 & 7.65 & 52.0 & 50.7 \\
\hline I 50 & 13804 & 13080 & 5.2 & 7.66 & $47 \cdot 3$ & 46.5 \\
\hline 160 & 16285 & I 5369 & 5.6 & 7.65 & 41.8 & 41.0 \\
\hline I7o & 19094 & I 806 I & $5 \cdot 4$ & $7.6 \mathrm{I}$ & 35.0 & 34.2 \\
\hline 180 & 22262 & 21259 & $4 \cdot 5$ & 7.53 & $25 \cdot 5$ & $24 \cdot 5$ \\
\hline 183 & 23288 & 22434 & 3.7 & 7.47 & 21.3 & 20.2 \\
\hline I 86 & 24350 & 23862 & 2.0 & $7 \cdot 38$ & I5. 0 & 13.9 \\
\hline 187.8 & 25005 & 25287 & I. I & 7.26 & 0 & 0 \\
\hline
\end{tabular}

A study of Table I shows that the value of $a$ decreases from about $4.7 \times 10^{6}$ at $0^{\circ} \mathrm{C}$. to $3.4 \times 10^{6}$ at $187.8^{\circ} \mathrm{C}$., the critical temperature. The values of $a_{1}, a_{2}$ and $a_{3}$ agree very well throughout, whereas in the case of $a_{4}$, its values near $0^{\circ}$ and near the critical temperature agree with those of $a_{1}, a_{2}$ and $a_{3}$, but at intermediate temperatures, $a_{4}$ is considerably less than $a_{1}, a_{2}$ and $a_{3}$. I am not able wholly to account for this divergence, although there is no doubt that some of the discrepancy may be due to errors in the assumed values of $p$ and $v_{2}$. As has been previously remarked, an error in the value of $p$ would have greater effect on the calculated value of $a_{4}$ than on that of $a_{3}$ or $a_{2}$. Note that $a_{1}$ is calculated without any use of the value of $p$. Its value is determined entirely by $v_{1}, v_{2}$ and $T$. In Table II the values of $p$ at the different temperatures have been calculated, using Equation 22 and $a_{1}$. The column is headed $p=$ $\frac{\mathrm{RT}}{b} e^{-\frac{a_{1}}{2 b \mathrm{RT}}}$, but exactly the same values are obtained when we use the equations

$$
p=\frac{\mathrm{RT}}{v_{1}-b} e^{-\frac{a_{1}}{v_{1} \mathrm{RT}}} \text { or } p=\frac{\mathrm{RT}}{v_{1}-b} e^{-\frac{a_{1}}{v_{2} \mathrm{RT}}} .
$$

It is to be noted that we should of course obtain the observed values of $p$, if instead of $a_{1}$ we had used $a_{2}, a_{3}$, or $a_{4}$ in the corresponding equations. Since $a_{2}$ and $a_{8}$ do not differ very much from $a_{1}$, it is evident that a small error in the value of $a$ will seriously affect the calculated values of $p$, except when the equation $p=\frac{\mathrm{RT}}{v_{2}-b} e^{-\frac{a}{v_{2} \mathrm{RT}}}$ is used to calculate $p$, in which case a considerable error in $a$ produces only a small change in $p$. 
If we compare the calculated with the experimental values of $p$, we notice that the maximum error amounts to $5.6 \%$ at about $30^{\circ}$ below the critical temperature. This error is, of course, considerable, but still hardly sufficient to invalidate the views here presented or to render them unworthy of discussion.

In Column 5 of Table II are given the values of the product $a b \times 10^{-6}$, and it will be at once evident that this product exhibits a noteworthy constancy throughout the whole temperature interval studied. Now for the two dozen or so substances which Young has investigated and for which he found $\left(-\alpha \mathrm{T}_{c} / s_{c}\right)$ to be nearly equal to unity, we deduced Equation 25, viz., $b_{\mathrm{T}}=b_{c} /\left(2-\mathrm{T} / \mathrm{T}_{c}\right)$. If the product $a b$ be supposed to be absolutely constant, we should have

$$
a_{\mathrm{T}}=a_{c}\left(2-\mathrm{T} / \mathrm{T}_{c}\right) \text {. }
$$

It must be clearly borne in mind that these results are supposed to hold only under the stated conditions and only below the critical temperature. Applied above this temperature, Equations 25 and $25 a$ would lead to results which are contrary to all experimental evidence. For at a temperature equal to twice the critical, $b$ would become infinity and $a$ would vanish.

In Column 6 of Table II are given the results obtained for the heat of vaporization of one gram of isopentane at the pressure of saturated vapor. " $L$ " includes the external work done during the increase of volume. I have not access to the original data of Young, but have put in Column 7 of Table II the results as quoted by Dieterici ${ }^{1}$ for the internal heat of vaporization, to which $I$ have added the calculated values of the external work, given by $p\left(v_{2}-v_{1}\right)$. In calculating $L$, we have used Equation 32 , according to which, $\mathrm{L}=2 \mathrm{RT} \log _{e} d_{1} / d_{2}=a_{1}\left(\mathrm{I} / v_{1}-\mathrm{I} / v_{2}\right)$. Assuming the values as quoted by Dieterici to be correct, our formula gives too high results, especially at low temperatures. Near $0^{\circ} \mathrm{C}$., the error amounts to $10 \%$ and becomes as low as $1.7 \%$ at $150^{\circ} \mathrm{C}$., increasing thereafter as we approach the critical temperature.

I have studied fluorobenzene, normal hexane, carbon tetrachloride with results quite similar to those obtained in the case of isopentane. I shall not take up space discussing them but proceed to a consideration of carbon dioxide.

Carbon Dioxide.-The results in Tables III and IV refer to one gram of carbon dioxide, but the unit of pressure is one atmosphere and the unit of voluthe one cubic centimeter. According to Amagat, ${ }^{2}$ from whom the data are taken, the critical temperature is $31.35^{\circ} \mathrm{C}$. The fifth column of Table IV contains values of the heat of vaporization obtained by Dieterici ${ }^{3}$ from Amagat's experimental results.

1. Ann. Physik, 9, I76 (1903).

2Ann. chim. phys., [6] 29, I18-136 (1893).

${ }^{3}$ Loc. cit. 
Table III.--Carbon Dioxide; UnIT Mass = I g.

\begin{tabular}{|c|c|c|c|c|c|c|c|}
\hline$t^{\circ} \mathrm{C}$ & $\begin{array}{l}y_{\mathrm{k}} \\
\mathrm{cc} .\end{array}$ & $\begin{array}{l}y_{2} \\
\text { ec. }\end{array}$ & $\begin{array}{l}b . \\
c c .\end{array}$ & Atm. $a_{1} \cdot c^{2}$ & $\begin{array}{c}a_{2} . \\
\text { Atma. }-\mathrm{cc}^{2} .\end{array}$ & $\begin{array}{c}c_{3} . \\
\text { Atm.-cc². }\end{array}$ & $\begin{array}{c}a_{4 .} \\
\text { Atm. }-\mathrm{cc}^{2} .\end{array}$ \\
\hline 0 & x.094 & 10.41 & 0.9900 & 2806 & $273 x$ & 2758 & 2414 \\
\hline 5 & 1. 126 & 8.772 & 0.9980 & $275 \mathrm{I}$ & 2680 & 2712 & 2443 \\
\hline so & I. I 68 & $7.5 \times 8$ & 1.0109 & 2719 & 2636 & 2671 & 2412 \\
\hline 15 & I .229 & 6.329 & 1.0292 & 2673 & 2595 & 2632 & 2404 \\
\hline 20 & I. 306 & 5.262 & I. .0463 & 2647 & 2549 & 2586 & 2400 \\
\hline 25 & I. 422 & $4 \cdot 167$ & 1. .0602 & $258 \mathrm{I}$ & 2493 & 2522 & 2408 \\
\hline 27 & $x .490$ & 3.759 & $x .0670$ & 2557 & $247^{2}$ & 2498 & 2408 \\
\hline 28 & 1.532 & $3 \cdot 547$ & I . 0699 & 2543 & 2461 & 2484 & 2407 \\
\hline 29 & I. 587 & 3.301 & I.0717 & 2523 & 2449 & 2468 & 2409 \\
\hline 30 & I. 672 & 2.994 & I. 0729 & 2494 & 2436 & 2449 & 2414 \\
\hline $3 x$ & I. 866 & $2.55 \mathrm{I}$ & 1.0777 & 2465 & 2427 & 2432 & 2420 \\
\hline $3 x \cdot 35$ & $2 . \times 55$ & 2.155 & I. .0775 & 2447 & 2421 & $242 \mathrm{I}$ & $242 \mathrm{I}$ \\
\hline
\end{tabular}

TABLE IV,-CARBon DIOXIDE; Unit MASS = I $g$.

$\begin{array}{ccccc}i^{\circ} \mathrm{C} . & P \text { (obs.). } & P=\frac{\mathrm{RT}}{b} e^{-\frac{a_{1}}{2 b \mathrm{RT}}} \text {. } & \begin{array}{c}\text { L (calc.). } \\ \text { Calories. }\end{array} & \text { L (Dieterici). } \\ 0 & 34.3 & 31.9 & 55.7 & 55.0 \\ 5 & 39.0 & 36.4 & 51.6 & 51.0 \\ 10 & 44.2 & 40.9 & 47.7 & 47.5 \\ 15 & 50.0 & 46.0 & 42.7 & 42.5 \\ 20 & 56.3 & 51.7 & 37.0 & 36.4 \\ 25 & 63.3 & 58.7 & 29.0 & 28.5 \\ 27 & 66.2 & 61.7 & 25.1 & 24.8 \\ 28 & 67.7 & 63.3 & 22.9 & 23.1 \\ 29 & 69.2 & 65.1 & 20.0 & 20.2 \\ 30 & 70.7 & 67.4 & 16.0 & 16.0 \\ 3 \mathrm{I} & 72.3 & 70.1 & 8.6 & 8.6 \\ 3 \mathrm{I} .35 & 72.9 & 7 \mathrm{I} .3 & 0 & 0\end{array}$

The results in Table III are somewhat similar to those for isopentane. Again $a_{1}, a_{2}$ and $a_{3}$ show general agreement, but the values of $a_{4}$ seem to be irregular, in no case diverging very much from the value at the critical temperature. Table IV shows again that the pressures calculated by our formula are usually too low, while on the other hand our calculated values of $\mathrm{L}$ agree very well with those of Dieterici.

The experiments of Amagat on the compressibility of carbon dioxide allow us to calculate $a$ and $b$ above the critical temperature. Amagat has given for a series of temperatures up to $258^{\circ} \mathrm{C}$. the minimum values of $p v$ as well as the corresponding pressures. His data are reproduced in Table V. Equations I 2 and I3, which concern us here, may be written as follows:

$$
\begin{gathered}
a=v(a / b-\mathrm{RT}) \\
\frac{a}{b \mathrm{RT}} e^{1-\frac{a}{b \mathrm{RT}}}=\frac{p v}{\mathrm{RT}}
\end{gathered}
$$

Using Equation 13 for any temperature and its corresponding value of 
$p o$, the value of $a / b \mathrm{R} T$ may be calculated by a rather laborious trial method; thence the value of $a / b$ is obtained, then $a$ from Equation 12 and finally $b$. A study of Amagat's results and his diagrams will show that although the minimum value of $p v$ may be determined with some accuracy, the value of the corresponding $p$; and hence of $v$, cannot be estimated so precisely. An error in locating the minimum of the curve, especially at high temperatures where the curves are rather flat, will not affect the value of $p v$ very much, but will seriously influence the value of $p$ and $v$. Hence at the highest temperatures, the values of the pressures as given by Amagat must be allowed to be less accurate than those at lower temperatures. Hence the ratio $a / b$ is probably more accurately determined than $a$ and $b$.

In Table $\mathrm{V}$ the unit mass of carbon dioxide is that which has a volume of $\mathrm{I}$ cc. at $0^{\circ} \mathrm{C}$. when the pressure is one atmosphere. In order to compare the results of Table III with those of Table V, the values of $a$ and $b$ in the former table must be divided by $(505.9)^{2}$ and 505.9 , respectively, since one gram of carbon dioxide occupies $505.9 \mathrm{cc}$. at $0^{\circ} \mathrm{C}$. and one atmosphere. If we select the values of $a$ and $b$ at $20^{\circ}$ and $30^{\circ}$ in Table III, we shall obtain in the new units: at $20^{\circ}, a=0.009960, b=0.002068$; at $30^{\circ}, a=0.009518, b=0.00212 \mathrm{I}$. These values agree very well indeed with those in Table $\mathrm{V}$ obtained in quite a different way.

\begin{tabular}{|c|c|c|c|c|c|c|c|}
\hline$t^{\circ} \mathrm{C}$. & Atm. & Minimum. & $\begin{array}{l}=\times 100 . \\
\text { cc. }\end{array}$ & $a / b \mathrm{RT}$ & $a / b$ & $\begin{array}{l}a \times 10^{4} . \\
\text { Atm. -ce. }\end{array}$ & $b \times 10 s$. \\
\hline 20 & 56.8 & o. I475 & 2597 & 4.497 & 4.868 & 9829 & 2019 \\
\hline 30 & 76 & 0.2185 & 2875 & 4.027 & $4 \cdot 508$ & $974 \mathrm{I}$ & $2 I 6 I$ \\
\hline 40 & IOI & 0.3083 & 3053 & 3.604 & $4 \cdot 168$ & 9192 & 2206 \\
\hline 50 & 125 & 0.3965 & 3172 & 3.294 & $3.93 \mathrm{I}$ & 8683 & 2209 \\
\hline 60 & 143 & 0.4830 & 3378 & 3.050 & 3.752 & 8519 & 2270 \\
\hline 70 & 162 & 0.5690 & 3512 & 2.847 & 3.608 & 8218 & 2278 \\
\hline 80 & 179 & 0.6500 & 3631 & 2.683 & 3.500 & 7972 & 2278 \\
\hline 90 & 196 & 0.7310 & 3730 & 2.538 & 3.404 & 7694 & 2260 \\
\hline 100 & 210 & 0.8140 & 3876 & 2.403 & 3.312 & 7495 & 2263 \\
\hline 137 & 245 & $1.085^{\circ}$ & 4429 & 2.053 & 3.109 & 7078 & 2271 \\
\hline 198 & 255 & I. $49^{20}$ & $585 \mathrm{I}$ & I. $66 \mathrm{I}$ & $2.89 \mathrm{I}$ & 6733 & 2329 \\
\hline 258 & 218 & 1.8100 & 8303 & I. 456 & 2.857 & 7433 & 2602 \\
\hline
\end{tabular}

The results shown in Table $\mathrm{V}$ indicate that $a$ continues to decrease above the critical temperature, while $b$, if it increases at all, increases very slowly. The values for $a$ and $b$ at $258^{\circ}$ and probably also at $198^{\circ}$ are likely subject to a considerable error, as has already been pointed out. Our results justify us therefore in saying that above the critical temperature and up to $200^{\circ} \mathrm{C} . b$ remains essentially constant in the case of carbon dioxide.

I may state here that results quite similar to those for carbon dioxide are obtained with ethylene, when Equations I2, I3 and I4 are applied 
to Amagat's results. In the case of ethylene also, $b$ seems to remain fairly constant from $10^{\circ}$ to $198^{\circ}$, while $a$ decreases as the temperature rises.

An application of the set of Equations 17 may be made to carbon dioxide. According to these equations, at the critical temperature, the value of the minimum $p v$ is $\frac{2}{e} p_{c} v_{c}$, the corresponding pressure is $1.104 p_{c}$ and the volume is $2 / 3 v_{c}$ or $4 / 3 b_{c}$. Now interpolating in Table $V$ between $30^{\circ}$ and $40^{\circ}$, we find for $31.35^{\circ}, p=79.4, p v=0.2302, v=0.002899$, while in the same units, $p_{c}=72.9, v_{c}=0.004260 . b_{c}=0.002130$. The calculated values for minimum $p v$ would be: $p=80.4, p v=0.2286$. $v=0.002840$, agreeing very well with the interpolated values.

Hydrogen.-In discussing hydrogen, we shall take as unit mass that quantity of hydrogen which occupies one cubic centimeter at $0^{\circ} \mathrm{C}$. and the pressure of one atmosphere. According to Witkowski, ${ }^{1}$ the behavior of this gas at $0^{\circ} \mathrm{C}$. is given accurately by the equation

$$
p v=0.999384+\frac{0.0006154}{v}+\frac{0.000000706}{v^{2}}
$$

The Dieterici equation at low pressures may be written

$$
p v=\mathrm{R} T+b p-a / v^{2} \text {. }
$$

If we imagine the pressure to be reduced indefinitely and the volume correspondingly increased, we find by comparing this equation with that of Witkowski that at $0^{\circ} \mathrm{C}$. RT $=0.9993^{8} 4$ and hence $\mathrm{R}=0.0036595$. To avoid any misconception, it might be explained that the reason this value of $R$ differs from $I / 273.09=0.0036618$, is because our unit mass of hydrogen which occupies one cubic centimeter under standard conditions, would occupy only $0.999384 \mathrm{cc}$. if it were a "perfect" gas. Hence the value of $R$ is smaller to that degree.

The critical temperature and pressure of hydrogen have been determined by a number of investigators. Bulle $^{2}$ has recently obtained the following values: $T_{c}=31.95 \pm 0 . I^{\circ}$ and $p_{c}=11.0$ atmospheres. Since $\mathrm{T}_{c}=a / 4 \mathrm{R} b$ and $p_{c}=a / 4 e^{2} b^{2}$, we obtain from Bulle's data, $a / b=$ $0.4677, a=0.000673$, and $b=0.001439$. The minimum values of $p v$ have been determined by Witkowski ${ }^{3}$ and by Kamerlingh Onnes and Braak. The earlier results of Witkowski agree fairly well with those of Onnes and Braak, although Witkowski states that his determinations of the pressures corresponding to a minimum po may be several atmospheres in error. The results obtained by applying Equations 12, I3

${ }^{1}$ Bull. acad. Cracovie, 6, 305-338 (1905).

2 Physik. Z., I4, 860-2; C. A., 7, 3877 (1913).

Loc. cit.

"Comm. Phys. Lab., Leiden, No. 97 (1907); quoted in Young's 'Stoichiometry," p. 24. 
and $I_{4}$ to the data of Witkowski and of Onnes and Braak are set forth in Tables VI and VII, respectively. Both tables would indicate that the ratio $a / b$ is approximately constant in the temperature interval under investigation. The results from Witkowski's data seem to show a decrease of both $a$ and $b$ with rise of temperature, while the presumably more accurate data of Onnes and Braak exhibit $a$ and $b$ as essentially constant from $-217^{\circ} \mathrm{C}$. to $-183^{\circ} \mathrm{C}$. The values of $a$ and $b$ in Tables VI and VII should be compared with those I have calculated from the critical data. In both tables the values of $a$ are considerably smaller than that of $a$ at the critical temperature; but whereas Witkowski's data indicate smaller values of $b$, those of Onnes and Braak give us values

TABLE VI.-HydRogen Data of Witkowski, $v=I$ AT $0^{\circ} \mathrm{C}$. WhEN $p=I$ ATM.

\begin{tabular}{|c|c|c|c|c|c|c|}
\hline $1^{\circ} \mathrm{C}$ & Atm. & $\begin{array}{l}\text { po. } \\
\text { Min. }\end{array}$ & $a / b \mathrm{RT}$ & $a / b$ & $\underset{\text { Atm. }}{a \times 10^{8}}$. & $b \times 100$ \\
\hline-183 & 32 & 0.3270 & I. I334 & 0.3737 & 449 & 1203 \\
\hline$-I 90$ & 43.5 & 0.2970 & 1.2329 & 0.3749 & 484 & 129 \\
\hline-205 & 55 & 0.2273 & I. 4920 & 0.3718 & 507 & 1363 \\
\hline-212 & 54.8 & 0.1926 & I. 6496 & 0.3688 & $5 \mathrm{II}$ & 138 \\
\hline
\end{tabular}

TABLE VII.-HYdRogen DaTA OF ONNES AND BRAak. $v=1$ AT $0^{\circ} \mathrm{C}$. WhEN $p=\mathrm{I}$ ATM.

\begin{tabular}{|c|c|c|c|c|c|c|}
\hline $0^{\circ} \mathrm{C}$. & $\underset{\text { Atm. }}{p .}$ & $\stackrel{p y .}{\text { Min. }}$ & $a / b \mathbf{R T}$. & $a / b$ & $\begin{array}{c}a \times 10^{6} \\
\text { Atm.-cc?. }\end{array}$ & $\begin{array}{c}6 \times 10^{8} . \\
\text { cc. }\end{array}$ \\
\hline-182.75 & $33 \cdot 36$ & 0.32630 & I. 1707 & 0.3870 & $55^{2}$ & 1426 \\
\hline-195.20 & 47.69 & 0.27338 & I. 3175 & 0.3756 & 519 & 1382 \\
\hline-204.62 & 52.10 & 0.22935 & I. $48 \mathrm{I} 6$ & 0.3712 & 531 & $\mathrm{I} 43 \mathrm{I}$ \\
\hline-209.6 & 53.73 & 0.20394 & I.60II & 0.3720 & 530 & 1425 \\
\hline-212.73 & 53.63 & o. I 8780 & I. 6827 & 0.3717 & 528 & I42I \\
\hline-217.32 & 51.57 & o. 16335 & I. 8234 & 0.3721 & 532 & 1430 \\
\hline
\end{tabular}

TABLE VIII.-Hydrogen. Data OF Witrowski.

\begin{tabular}{|c|c|c|c|c|}
\hline $\begin{array}{l}\text { (Atm.) } \\
\text { Witkowski. }\end{array}$ & $t=\frac{-183^{\circ} \mathrm{C} .}{p(\text { calc }) .}$ & $t=\frac{-190^{\circ} \mathrm{C} .}{p(\text { calc.). }}$ & $t=-205^{\circ} \mathrm{C}$. & $t=-212^{\circ} \mathrm{C}$ (calc.). \\
\hline I & I.004 & I.,005 & 1.006 & 1.009 \\
\hline 5 & 5.008 & 5.010 & 5.014 & 5.026 \\
\hline 10 & 9.997 & 9.995 & 10.003 & 10.016 \\
\hline$x_{5}$ & 14.995 & 14.990 & 14.986 & 15.013 \\
\hline 20 & 20.013 & 20.007 & 19.989 & 20.089 \\
\hline 25 & 25.011 & 24.999 & 25.023 & 25.065 \\
\hline 30 & 30.002 & 30.005 & 30.058 & 30.088 \\
\hline 35 & 35.003 & 35.000 & 35.093 & 35.139 \\
\hline 40 & 40.024 & 40.007 & 40.079 & 40.167 \\
\hline 45 & 45.028 & $45 . \infty 03$ & 45.036 & 45.126 \\
\hline 50 & 50.020 & 49.997 & 50.005 & 50.026 \\
\hline 55 & 54.997 & 54.977 & 55.000 & 54.998 \\
\hline 60 & 59.955 & $59.95^{8}$ & 60.007 & 60.052 \\
\hline
\end{tabular}

not appreciably different from the value of $b$ at $32^{\circ}$ absolute. We shall, however, shortly produce evidence indicating that, above $-183^{\circ} \mathrm{C}$. at least, $a$ and $b$ for hydrogen do decrease with rise of temperature. Before proceeding to this, I desire to illustrate how well the Dieterici equa- 
tion reproduces the Witkowski data. Witkowski ${ }^{1}$ gives a table containing the values of $p v$ at a series of temperatures from $100^{\circ} \mathrm{C}$. to $-212^{\circ} \mathrm{C}$. and up to a pressure of 60 atmospheres. In Table VIII I have given the results of calculating the pressures corresponding to volumes as given by Witkowski and at the temperatures $-183^{\circ},-190^{\circ},-205^{\circ}$, and $-212^{\circ} \mathrm{C}$.

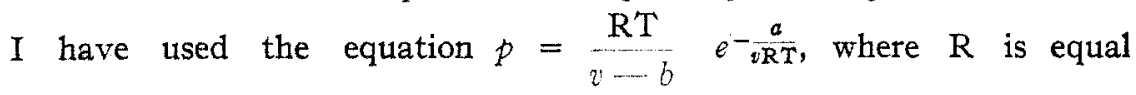
to 0.0036595 , and the values of $a$ and $b$ for each temperature are taken from Table VI. The agreement of the calculated pressures with those given by Witkowski is certainly very excellent. It is to be noted that the values of $a$ and $b$ which have been employed have not been deduced from the whole course of the pv curve, but in each case from its minimum value only.

According to Equation $7 a$, we have the relation

$$
\left.\begin{array}{rl}
\left(\frac{d p}{d \mathrm{~T}}\right)_{v} & =\frac{p}{\mathrm{~T}}\left(\mathrm{I}+\frac{a}{v \mathrm{RT}}+\frac{\mathrm{T}}{v-b} \cdot \frac{d b}{d \mathrm{~T}}-\frac{\mathrm{I}}{v \mathrm{R}} \frac{d a}{d \mathrm{~T}}\right) \\
& =\frac{\mathrm{R}}{v-b} e^{-\frac{a}{v \mathrm{RT}}}\left(\mathrm{I}+\frac{a}{v \mathrm{RT}}+\frac{\mathrm{T}}{v-b} \frac{d b}{d \mathrm{~T}}-\frac{\mathrm{I}}{v \mathrm{R}} \frac{d a}{d \mathrm{~T}}\right)
\end{array}\right\}
$$

If $a$ and $b$ are constants, or if the expression $(\mathrm{T} /(v-b), d b / d \mathrm{~T}-\mathrm{I} / v \mathbf{R}$ $d a / d T)$ vanishes, we have the simpler equations

$$
\left(\frac{d p}{d \mathrm{~T}}\right)_{v}=\frac{p}{\mathrm{~T}}\left(\mathrm{I}+\frac{a}{v \mathrm{RT}}\right)=\frac{\mathrm{R}}{v-b} e^{-\frac{a}{v \mathrm{RT}}}\left(\mathrm{I}+\frac{a}{v \mathrm{RT}}\right) .
$$

In most cases, where $v$ is not too small, we could write

$$
\left(\frac{d p}{d \mathrm{~T}}\right)_{v}=\frac{\mathrm{R}}{v-b}
$$

I have assumed that the expression $\frac{\mathrm{T}}{v-b} \frac{d b}{d \mathrm{~T}}-\frac{\mathrm{I}}{v \mathrm{R}} \frac{d a}{d \mathrm{~T}}$, in what follows, is very small, compared with $a / v \mathrm{R} T$ in the case of hydrogen, at least throughout the temperature interval $-183^{\circ} \mathrm{C}$. to $100^{\circ} \mathrm{C}$. The grounds for this will be discussed later. I have accordingly used Equation 7 to determine $a$ and $b$, calculating $(d p / d \mathrm{~T})_{v}$ and $\mathrm{P} / \mathrm{T}$ from the Witkowski data. In his memoir, Witkowski gives the pressures at the series of temperatures, $100^{\circ}, 0^{\circ},-77^{\circ},-104^{\circ},-147^{\circ},-183^{\circ},-190^{\circ},-205^{\circ}$, and $-212^{\circ} \mathrm{C}$., corresponding to a series of volumes from $\mathrm{I}$ to $\mathrm{I} / 60$ in terms of the volume at $0^{\circ} \mathrm{C}$. and one atmosphere. The method I employed to obtain an accurate estimate of $(d p / d \mathrm{~T})_{0}$ at each temperature will be clear from the following example: Corresponding to the volume $v=1 / 40$, Witkowski gives for the temperatures $-77^{\circ},-104^{\circ}$, and $-147^{\circ} \mathrm{C}$. the pressures $29.33,25.22$ and 18.63 , respectively. An equation of the second degree in $T$ was found algebraically which would re-

1 Loc. cit. 
produce the pressures at the three temperatures. From this equation, the values of $(d p / d T)$, at $-104^{\circ}$ was easily calculated. Geometrically, having pressures as ordinates and temperatures as abscissae, a parabola was found which would go through the three points and the slope at the intermediate point was the value sought. The parabola, of course, in no case departs much from a straight line. To find $(d p / d T)_{8}$ at $-I_{47}{ }^{\circ} \mathrm{C}$., the data for $-104^{\circ},-147^{\circ}$ and $-183^{\circ}$ were used and so on for all the other temperatures. It is evident that the values we have obtained for $(d p / d T)_{0}$ will, in all probability, be more accurate at higher temperatures than at lower ones. The pressures at $0^{\circ} \mathrm{C}$. are more than four times as great as at $-205^{\circ} \mathrm{C}$., and as $(d p / d \mathrm{~T})_{v}$ is obtained by a different method, the probable error at $-205^{\circ}$ will be four times as great as at $0^{\circ} \mathrm{C}$., assuming that the pressures in both cases have been determined with the same relative accuracy. I have determined $(d p / d T)_{v}$, and hence $a$ and $b$, using the data for the volumes $1 / 60, I / 50, I / 40,1 / 30$ and $I / 20$ for the temperatures already named, excluding the highest and the lowest one. Here again the accuracy of the calculated result will, for obvious reasons, be inversely proportional to the volume selected. This will be illustrated by the results obtained at the various volumes, although there is a surprising agreement in nearly all cases.

In Table IX are given the detailed results for $v=1 / 60$, while Table $\mathrm{X}$ contains only the final results for $a, b$, and $a / b$, with the averages in the last column, excluding from the average the results for $v=1 / 20$, which are likely to be least accurate. Table XI is simply a summary of these average values together with the values for $100^{\circ} \mathrm{C}$., obtained by a rather uncertain extrapolation. As emphasized previously, the results at low temperatures are probably less trustworthy than those at higher temperatures. An examination of these tables shows that $a$ and $b$ decrease with rise of temperature. With regard to the ratio $a / b$, the same statement may actually be true, in spite of the fact that from $-205^{\circ}$ to $-147^{\circ}$ the tables indicate a slight increase with the temperature. The results at low temperatures are, however, subject to such error that it is unsafe to indulge in much generalizing. An important point to be noted, however, is that the values of $a, b$, and also $a / b$, as found by the present method for $-\mathrm{I} 83^{\circ},-190^{\circ}$ and $-205^{\circ} \mathrm{C}$., agree remarkably well with those given in Tables VI and VII, found by a quite different method. The equation of state for a gas at low pressures can be written in the form $p v=\mathrm{RT}+$ $p\left(b-a / \mathrm{R}^{\prime}\right)$, which at $0^{\circ} \mathrm{C}$. is equivalent to $p v=\mathrm{R} T+p(b-a)$, since $\mathrm{RT}$ is approximately unity. Comparing this with Witkowski's empirical equation already given, we find the value of $(b-a)$ at $0^{\circ} \mathrm{C}$. to be 0.0006154 . From Table XI we obtain a result in very satisfactory agreement with this value, viz., $(b-a)=0.000622$. 
TABL IX.-HYDROGEN. $v=1$ AT $0^{\circ} \mathrm{C}$. WHEN $p=\mathrm{I}$ ATM.

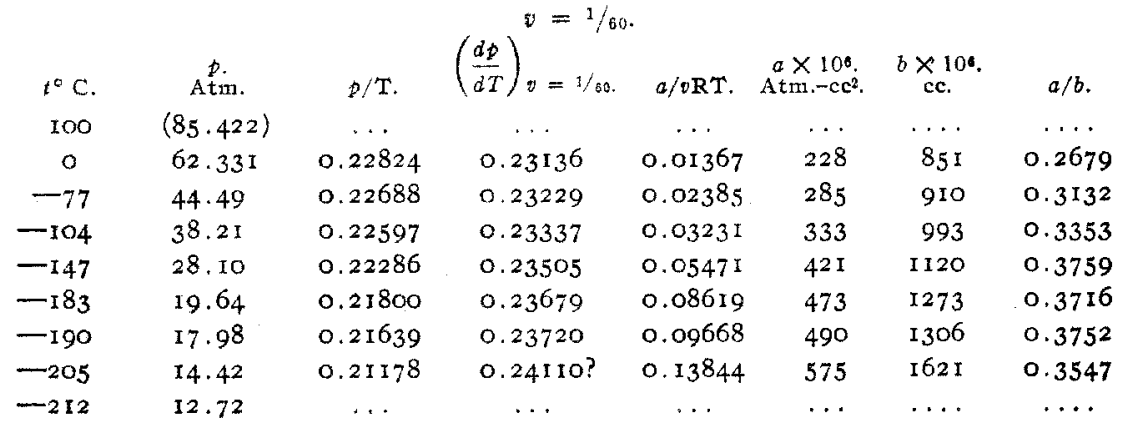

TABLE X.-Hydrogen. a AND $b$ MULTiplied By $10^{6}$.

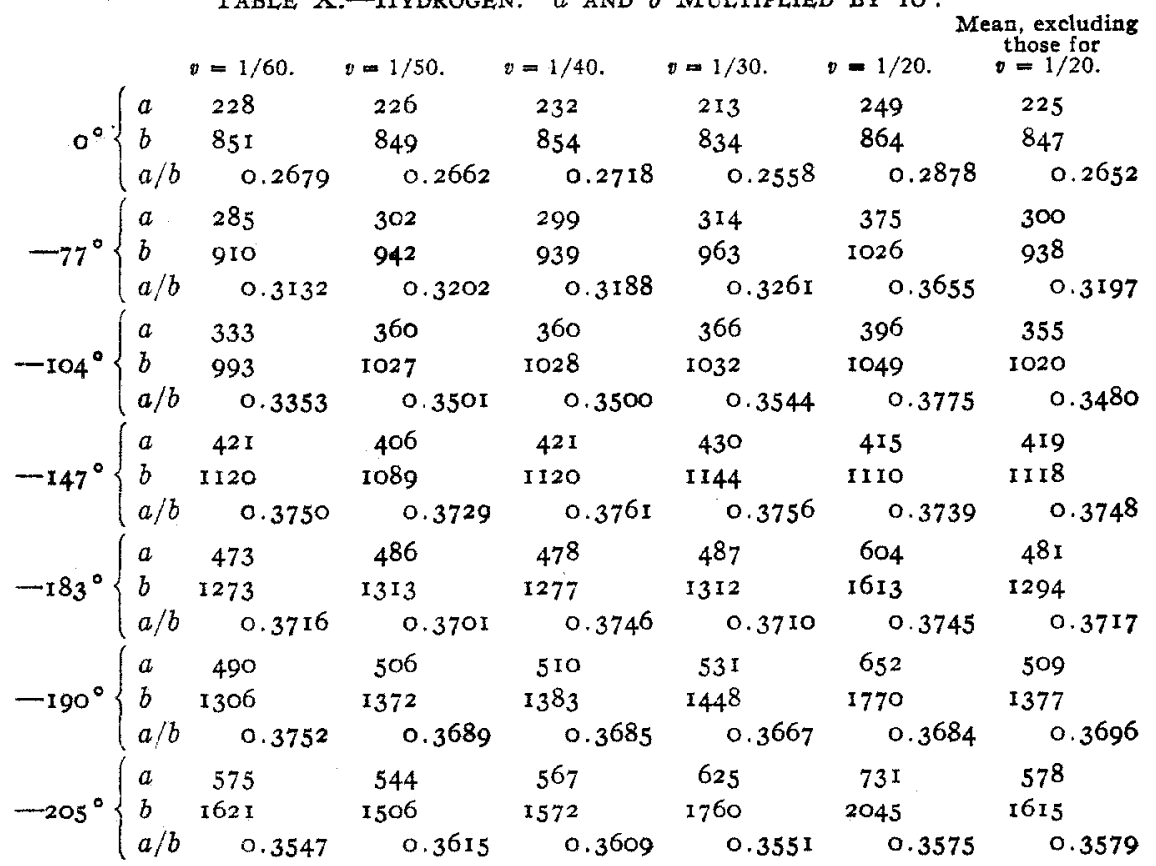

Table XI.-Hydrogen. Average Values of $a, b$ and $a / b$ from Tarle $X$.

$0^{\circ} . \quad-77^{\circ} . \quad-104^{\circ} . \quad-1479^{\circ}$. $-183^{\circ} . \quad-190^{\circ}$. $-205^{\circ}$. (extrapolated). $\begin{array}{lllllllll}a \times 10^{\circ} & 225 & 300 & 355 & 419 & 48 \mathrm{I} & 509 & 578 & 170 \text { ? }\end{array}$ $b \times 10^{6} 847 \quad 938 \quad 1020 \quad I 118 \quad 1294 \quad 1377 \quad 1615 \quad 800$ ? $\begin{array}{llllllllll}a / b & 0.2652 & 0.3197 & 0.3480 & 0.3748 & 0.3717 & 0.3696 & 0.3579 & 0.2125 ?\end{array}$

For an ideal gas, we have the relation $p / T=R / v$. For the mass of hydrogen which we are taking as our unit and for a value of $v$ equal to $1 / 60$, the theoretical value of $p / T$ would be 0.21957 . An examination of the third column of Table IX will show that somewhere between $-r_{4} 7^{\circ}$ 
and $-183^{\circ}, p / T$ has its "theoretical" value. By interpolation, we find this temperature to be $-\mathrm{I} 7 \mathrm{I} \cdot 4^{\circ}$. If we investigate the data for $v=1 / 50$, $\mathrm{I} / 4 \mathrm{O}, \mathrm{I} / 3 \mathrm{O}$ and $\mathrm{I} / 20$, we obtain the following results for this temperature, viz., - $171.4^{\circ},-170.3^{\circ},-157.5^{\circ},-167.0^{\circ}$. Since the results for $v=1 / 60$ and $I / 50$ are the most accurate, we may accept $-171.4^{\circ} \mathrm{C}$. as very close to the temperature at which $p / T=R / v$. Now, according to the equation of state, for moderate pressures,

$$
\frac{p}{\mathrm{~T}}=\frac{\mathrm{R}}{v-b} e^{-\frac{a}{v \mathrm{RT}}}=\frac{\mathrm{R}}{v}\left(\mathrm{I}+\frac{b}{v}-\frac{a}{v \mathrm{RT}}\right) .
$$

Evidently $p / \mathrm{T}$ will equal $\mathrm{R} / v$ when $b=a / \mathrm{RT}$, or $a / b=\mathrm{RT}$. Since we have found the temperature to be $-171.4^{\circ}$, we calculate for this temperature $a / b=\mathrm{RT}=0.372 \mathrm{I}$, in excellent agreement with the values of $a / b$ in Table XI. At the temperature -I $71.4^{\circ} \mathrm{C}$. or Ior $.6^{\circ}$ absolute, the $p v$ curve for hydrogen would just fail to have a minimum and would proceed virtually horizontally for several atmospheres. At this temperature, the behavior of hydrogen under moderate pressures would be given very accurately by Boyle's law.

Joule-Thomson Effect for Hydrogen.-The values we have obtained for $a$ and $b$, at least at $0^{\circ}$ and $100^{\circ} \mathrm{C}$., are confirmed if we consider their relation to the Joule-Thomson effect. According to the experiments of Joule, ${ }^{1}$ the value of $\Delta \mathrm{T} / \Delta p$ of Equation 34 , at $6.8^{\circ} \mathrm{C}$. is -0.030 , and at $90 . \mathrm{I}^{\circ} \mathrm{C}$. is -0.044 . We can use at $6.8^{\circ} \mathrm{C}$. the values of $a$ and $b$ for $0^{\circ} \mathrm{C}$. Their values near $100^{\circ} \mathrm{C}$. will be less and a rough extrapolation gives us for $100^{\circ} \mathrm{C}$., $a=0.000170$, and $b=0.000800$. Using our values of $a$ and $b$ in Equation 34, the calculated value of $\Delta \mathrm{T} / \Delta p$ at $6.8^{\circ}$ C. would be -0.032 , and at $90 . I^{\circ} \mathrm{C}$. $\multimap .043$, in good agreement with the observed values. The negative lowering means, of course, an elevation of temperature.

Whether there shall be a rise or a fall in temperature in the Joule-Thomson experiment depends on whether $(2 a / \mathrm{RT}-b)$ is negative or positive. For most gases at ordinary temperatures $b$ is less than $2 a / \mathrm{RT}$ and we have a fall in temperature. In the case of hydrogen at ordinary temperatures $(2 a / \mathrm{RT}-b)$ is negative and we have a rise in temperature. At a sufficiently low temperature the sign should be reversed. The inversion temperature for hydrogen has been found by Olszewski ${ }^{2}$ to be $-80.5^{\circ} \mathrm{C}$. or $192.5^{\circ}$ abs. At this temperature, then, we should have $(2 a / \mathrm{RT}-b)=$ o. Now using the values given in Table XI, at $-77^{\circ} \mathrm{C}$., $(2 a / \mathrm{RT}-b)=$ $\longrightarrow 0.000102$ and at $-104^{\circ}$ C. $(2 a / \mathrm{RT}-b)=+0.000128$. Accordingly, at about $-89^{\circ} \mathrm{C}$. or $184^{\circ}$ abs. $(2 a / \mathrm{RT}-b)$ would be zero. We therefore calculate the inversion temperature to be $184^{\circ}$ instead of $192.5^{\circ}$

1 Landolt-Börnstein's Tabellen, 1912, p. 786.

'Bull. acad. Cracovie, I901, p. 453; quoted in Young's "Stoichiometry," p. 236. 
abs. as observed by Olszewski. This investigator later observed in the case of nitrogen and oxygen that the inversion temperature depends on the initial pressure. Equation 34 in its most rigorous form would also show that this must be the case. In any event, the fair agreement of our value with that observed by Olszewski is another confirmation of the approximate correctness of the values we have obtained for $a$ and $b$.

We are now in a better position to consider the assumption we have made that in the equation

$$
\left[\frac{d p}{d \mathrm{~T}}\right]_{v}=\frac{p}{\mathrm{~T}}\left[\mathrm{I}+\frac{a}{v \mathrm{RT}}+\frac{\mathrm{T}}{v-b} \frac{d b}{d \mathrm{~T}}-\frac{\mathrm{I}}{v \mathrm{R}} \frac{d a}{d \mathrm{~T}}\right]
$$

we may suppose $\frac{T}{v-b} \frac{d b}{d T}-\frac{\mathbf{I}}{v \mathbf{R}} \frac{d a}{d \mathrm{~T}}$ to be negligible with respect to $a / v \mathrm{RT}$. All our values from $-205^{\circ}$ to $0^{\circ} \mathrm{C}$. have been calculated on this assumption, in applying Equation 7 . The assumption seems to have been justified by the following facts: (I) The values we have obtained at $-183^{\circ}$ and $-190^{\circ}$ (cf. Table XI) agree well with those calculated from the minimum values of $p v$ (cf. Tables VI and VII). When the values of $a$ and $b$ from Table XI are used in the equation $p=$ $\frac{\mathrm{RT}}{v-b} e^{-\frac{a}{v \mathrm{RT}}}$, the experimental results of Witkowski are reproduced with great accuracy (cf. Table VIII). (3) At $0^{\circ} \mathrm{C}$., our values of $a$ and $b$ agree well with the value of $\left(b-a / \mathrm{R}^{\top} \mathrm{T}\right)$ or $(b-a)$ deduced from Witkowski's empirical equation. (4) Our values of $a$ and $b$ at $0^{\circ} \mathrm{C}$. and $100^{\circ} \mathrm{C}$. lead us to an estimate of the Joule-Thomson effect in good agreement with experiment. (5) Our calculation of the inversion temperature agrees passably well with Olszewski's observation. (6) At $0^{\circ} \mathrm{C}$. the value of $(b-a / \mathrm{RT})$, or in this case $(b-a)$, is determined with some degree of precision by Witkowski's work to be close to 0.000620 . All our experience with isopentane, carbon dioxide and other substances not considered in this paper goes to show that $a$ always decreases with rise of temperature. Since at the critical temperature and around $-183^{\circ} \mathrm{C}$., $(b-a)$ is much greater than 0.000620 , the value of $b$ must decrease with rise of temperature to $0^{\circ} \mathrm{C}$. Since $a$ and $b$ decrease together, the terms $\frac{\mathrm{T}}{v-b} \frac{d b}{d \mathrm{~T}}$ and $-\frac{\mathrm{I}}{v \mathrm{R}} \frac{d a}{d \mathrm{~T}}$ will tend to neutralize each other; and the preceding statements go to show that this neutralization is fairly complete.

These considerations seem to justify the assumption $I$ have made and to render the values of $a$ and $b$ which I have obtained worthy of some degree of confidence. That $b$ decreases with rise of temperature, at least above $-183^{\circ} \mathrm{C}$., is a result in harmony with the views expressed by $T$. W. Richards ${ }^{1}$ in regard to the compressibility of atoms. He shows that

1 Thrs JourNaI, 36, 617 (1914); 37, 2417 (1915). 
the value of $b$ for helium (assuming that $a$ is negligible) decreases from $0^{\circ} \mathrm{C}$. to $100^{\circ} \mathrm{C}$., and explains the decrease as due to the increasing collision-pressure with increase of temperature. Whatever be the explanation, we have found that the same thing is true of $b$ for hydrogen, its value at $0^{\circ} \mathrm{C}$. being about $60 \%$ of that at the critical temperature.

Our calculations for helium are also in harmony with those of $T . W$. Richards. According to Kamerlingh Onnes, ${ }^{1}$ the critical temperature for helium is $5.25^{\circ}$ abs. and the critical pressure 1718 millimeters, or $2.26 \mathrm{I}$ atmospheres. From these data we obtain $a=0.000089$ and $b=0.00 I_{5} \mathrm{I}$, where the unit quantity of helium occupies one cubic centimeter under standard conditions. Evidently the value of $a$ is very small and at ordinary temperatures one is probably justified in considering $a / \mathrm{RT}$ negligible with reference to $b$. If we take $4 \mathrm{~g}$. of helium as our unit mass, the value of $b$ at $5.25^{\circ}$ abs. is $25.6 \mathrm{cc}$. At $0^{\circ} \mathrm{C}$. and at $100^{\circ} \mathrm{C}$. Richards finds $(b-a / \mathrm{RT})$ or in this case, very approximately, $b$, equal to $12 \mathrm{cc}$. and $10.4 \mathrm{cc}$., respectively. The value of $b$ at $0^{\circ} \mathrm{C}$. is thus less than half what it is calculated to be at $5.25^{\circ}$ absolute.

In the case of hydrogen, however, the value of $a / \mathrm{RT}$ is not negligible with respect to $b$ and for this reason fairly accurate values of both must be determined before one can say whether $b$ decreases or not with the temperature. Thus Richards finds an increase in $(b-a / \mathrm{RT})$ for hydrogen as one goes from $0^{\circ} \mathrm{C}$. to $100^{\circ} \mathrm{C}$. In spite of this fact, we have found that both $a$ and $b$ decrease in this interval. Richards, of course, fully understood that this might be the case, if the value of $a$ were sufficiently large.

Richards has also expressed the view that $b$ does not differ very much from the volume of the liquefied gas. Our results are so far in agreement with this, that we have found $b$ at temperatures considerably below the critical temperature to be but slightly smaller than the volume of the liquid, as is apparent from the equation $\mathrm{I} / \mathrm{b}=\mathrm{I} / v_{1}+\mathrm{I} / v_{2}$.

So far we have not particularly concerned ourselves with the question as to whether $a$ and $b$ in addition to being temperature, are also volume functions. The critical state is determined mathematically by the condition that $(d p / d v)_{T}$ and $\left(d^{2} p / d v^{2}\right)_{T}$ shall both be zero. Assuming $a$ and $b$ to be independent of the volume has led to results in conformity with experience; for example, to the result that the critical density is 3.695 times as great as the density would be for an "ideal" gas at the critical temperature and pressure. I have therefore felt myself justified in inferring that $a$ and $b$ are essentially independent of the volume within the limits of pressure considered in this paper. It is only right to state, however, that when very great pressures are considered, it seems

${ }^{1}$ C. A., 7, 2327 (1913). 
necessary, as a result of some calculations I have made, to assume that $b$ under these circumstances suffers a diminution in volume. This question I have, however, not investigated thoroughly, partly owing to the lack of available, accurate data.

As a result of the investigation set forth in this paper, I consider that the following statements are justified: The Dieterici equation of state has a sounder theoretical basis than that of van der Waals. It reproduces the behavior of a gas, not only at low pressures, but also at the critical point and even at much higher pressures. Although, perhaps, not so simple an expression as van der Waals's, many of the deductions from it are characterized by great simplicity and elegance. It has of course the great advantage over the van der Waals equation that it reproduces the critical state accurately, whereas the latter, as is well known, does not. It seems to me, therefore, that we ought to abandon the van der Waals equation, except as a qualitative interpretation of the facts, and adopt the Dieterici equation of state as the only one which has both a sufficiently sound theoretical foundation and a sufficiently accurate correspondence with the facts.

\section{Summary.}

In the present paper I have discussed the Dieterici equation of state, $p=\frac{\mathrm{RT}}{v-b} e^{-\frac{a}{v T T}}$ in some detail and have indicated in a number of ways how accurately it reproduces the experimental results.

Various methods are developed for calculating the values of $a$ and $b$ below, at, and above the critical temperature.

A formula is deduced for calculating the pressure of saturated vapor from the densities of the liquid and vapor.

A formula is deduced for calculating the latent heat of vaporization from the densities of liquid and saturated vapor.

Isopentane, carbon dioxide and hydrogen are studied in some detail. In the case of isopentane, $a$ decreases and $b$ increases from $0^{\circ} \mathrm{C}$. up to the critical temperature. The same is true of carbon dioxide. Above the critical temperature, in the case of carbon dioxide, $a$ continues to decrease, while $b$ remains fairly constant up to $200^{\circ} \mathrm{C}$. In the case of hydrogen, $a$ decreases from the critical temperature up to ordinary temperatures, while $b$ does the same, from $-183^{\circ} \mathrm{C}$. at least.

In the case of hydrogen, its inversion temperature is calculated, and also the temperature at which it "obeys" Boyle's law for moderate pressures. The latter temperature was calculated to be $-I 7 \mathrm{I} .4^{\circ} \mathrm{C}$.

Combining the law of Cailletet and Mathias with a result obtained by Young for a number of substances, it is shown that the density of a substance at the absolute zero is four times the critical density.

Our conclusions in regard to the variation of $b$ with the temperature 
are shown to be in harmony with some of the views of $T$. W. Richards in regard to the compressibility of atoms.

Calgary, alberta, and Minneapolts, Minnesota.

[CONTRIBUTION FROM THE Chemical Laboratories OF Columbia University. No. 259.]

\section{THE PROPERTIES OF MIXED LIQUIDS. I. SULFURIC ACID- WATER MIXTURES.}

By J. Iivingston R. Morgan and Charke Edwin Davis.

Received December 29, 1915.

This paper is the first report upon a somewhat extended series of investigations, started some two years ago, upon the drop weights, or surface tensions, of pure liquids, at many temperatures, and their relationship to the values of that property in their binary or other admixtures in various proportions, at those temperatures. The main object of the work is to provide such a further, perhaps more consistent, set of experimental data that eventually it may perhaps be possible to find the cause of the mutual effects of liquids upon one another; which, although absent in some cases, are great, and yet of widely differing magnitude, in others.

For some binary liquid mixtures it is known that the so-called law of mixtures holds more or less rigidly, $i . e$. , the value of a certain physical property of the mixture is equal to the sum of the values of that property for the pure constituents under like conditions, each multiplied by the ratio of its weight in the mixture, to the total weight of the system. Or, expressed as an equation, $\mathrm{P}_{\text {Mixt. }}=x \mathrm{P}_{a}+(\mathrm{I}-x) \mathrm{P}_{b}$, where the terms $P$ represent the values of the property considered, and $x$ is the weight of the constituent $a$, when the total weight of the mixture is regarded as unity. In all cases of this sort it is generally assumed, apparently with reason, (I) that no chemical reaction has taken place between the constituents, and (2) that the previous molecular state of each constituent in the pure condition still persists in their mixture.

The great mass of binary liquid mixtures, however, not only fails to follow this law, but shows a variation from it which depends solely upon the constituents selected, and upon the proportions in which they are mixed. From the fact that following the law of mixtures is regarded as indicating that a system is free from any chemical interaction between its constituents, and that the molecular states of its constituents are unaltered as a result of the mixing, it is natural to assume that a system which does not follow this law is one in which either a chemical reaction has taken place, or in which the constituents have undergone a molecular change, of the nature of a breaking down of a previous polymerization of one or both of the individuals, for example.

Many investigators, ignoring the second possible cause of change, 